\title{
Extracellular vesicles for acute kidney injury in preclinical rodent models: a meta- analysis
}

Chao Liu', Jin Wang ${ }^{1}$, Jie Hu²,3 Bo Fu', Zhi Mao ${ }^{2}$, Hengda Zhang ${ }^{1}$, Guangyan Cai ${ }^{1}$, Xiangmei Chen ${ }^{1}$ and Xuefeng Sun ${ }^{1 *}$ D

\begin{abstract}
Introduction: Extracellular vesicles (EVs), especially stem cell-derived EVs, have emerged as a potential novel therapy for acute kidney injury (AKI). However, their effects remain incompletely understood. Therefore, we performed this meta-analysis to systematically review the efficacy of EVs on AKI in preclinical rodent models.

Methods: We searched PubMed, EMBASE, and the Web of Science up to March 2019 to identify studies that reported the treatment effects of EVs in a rodent AKI model. The primary outcome was serum creatinine (Scr) levels. The secondary outcomes were the blood urea nitrogen (BUN) levels, renal injury score, percentage of apoptotic cells, and interleukin (IL)-10 and tumour necrosis factor (TNF)-a levels. Two authors independently screened articles based on the inclusion and exclusion criteria. The meta-analysis was conducted using RevMan 5.3 and R software.

Results: Thirty-one studies $(n=552)$ satisfied the inclusion criteria. Pooled analyses demonstrated that the levels of $\operatorname{Scr}(\mathrm{SMD}=-3.71 ; 95 \% \mathrm{Cl}=-4.32,-3.10 ; P<0.01)$, BUN (SMD $=-3.68 ; 95 \% \mathrm{Cl}=-4.42,-2.94 ; P<0.01)$, and TNF- $a$ $(\mathrm{SMD}=-2.65 ; 95 \% \mathrm{Cl}=-4.98,-0.32 ; P<0.01)$; the percentage of apoptotic cells $(\mathrm{SMD}=-6.25 ; 95 \% \mathrm{Cl}=-8.10$, 4.39; $P<0.01)$; and the injury score $(\mathrm{SMD}=-3.90 ; 95 \% \mathrm{Cl}=-5.26,-2.53 ; P<0.01)$ were significantly decreased in the EV group, and the level of IL-10 (SMD $=2.10 ; 95 \% \mathrm{Cl}=1.18,3.02 ; P<0.01)$ was significantly increased.

Meanwhile, no significant difference was found between stem cell-derived EVs and stem cells.

Conclusion: The present meta-analysis confirmed that EV therapy could improve renal function and the inflammatory response status and reduce cell apoptosis in a preclinical rodent AKI model. This provides important clues for human clinical trials on EVs.
\end{abstract}

Keywords: Extracellular vesicles, Exosomes, Mesenchymal stromal cells, Acute kidney injury, Meta-analysis

\section{Background}

Acute kidney injury (AKI) is a major kidney disease characterised by a rapid decline in renal function and is associated with an increase in mortality and hospitalisation [1]. However, the prognosis of this disease, which may occur under various circumstances, has not been significantly improved since the mid-1990s [2]. Due to the lack of efficient therapeutic methods, patients with renal ischaemia

\footnotetext{
* Correspondence: xfssun@126.com

'Department of Nephrology, Chinese PLA General Hospital, Chinese PLA Institute of Nephrology, State Key Laboratory of Kidney Diseases, National Clinical Research Center for Kidney Diseases, 28 Fuxing Road, Beijing, China Full list of author information is available at the end of the article
}

reperfusion injury (IRI) are mostly treated by supportive manoeuvres, such as renal replacement therapy [3].

Many studies have confirmed that mesenchymal stem cell (MSC) therapy can effectively improve AKI $[4,5]$, but most of these studies have not found that MSCs colonise in the kidneys to play a direct role $[4,6]$. Moreover, MSC therapy may have certain risks, such as inducing tumours, and its safety remains questionable [7].

Recently, data in the literature have highlighted that the delivery of MSC-derived EVs can ameliorate AKI in preclinical models $[3,6,8]$. EVs are secreted by almost all types of cells and can be subdivided into exosomes, 
microvesicles, and apoptotic bodies [9]. Exosomes are the smallest vesicles $(30-100 \mathrm{~nm})$ released by the fusion of multivesicular bodies containing intraluminal vesicles with the plasma membrane. Microvesicles are vesicular structures $(0.1-1.0 \mu \mathrm{m})$ shed by outward blebbing of the plasma membrane. The largest EVs $(1-5 \mu \mathrm{m})$ are apoptotic bodies that are formed during the late stages of apoptosis [10]. EVs contain proteins, lipids, carbohydrates, mRNAs, and miRNAs and may influence different cell types acting on physiological processes such as proliferation and immune escape [11]. Compared with MSCs, the small size of MSC-derived EVs allows them to avoid the pulmonary first-pass effect and to penetrate deep inside most body barriers [3]. Therefore, MSCderived EVs are expected to be an effective treatment for AKI.

Many animal studies have been performed to investigate the efficacy of EVs on an AKI model with various cell origins and different injection doses, delivery routes, and therapy times $[3,12]$. To provide the most recent available evidence for clinical studies, we performed this meta-analysis to investigate the efficacy of EVs on preclinical rodent models.

\section{Materials and methods}

Preferred Reporting Items for Systematic Reviews and Meta-Analyses (PRISMA) was used to perform this meta-analysis [13].

\section{Search strategy}

We searched PubMed, EMBASE, and the Web of Science from database inception to March 2019. The search terms were as follows: "extracellular vesicles" or "EVs" or "micro vesicles" or "micro-vesicles" or "microvesicles" or "microparticle" or "exosome" or "MVs" or "shedding vesicles") and ("AKI" or "acute kidney injury" or "renal ischaemia-reperfusion" or "acute renal failure"). The search was limited to rodent models with no language restrictions. The reference lists of selected studies were searched by hand to identify potentially relevant citations. Ethical approval was not required because the meta-analysis was based on published articles.

\section{Study selection}

Two independent investigators (CL and JW) conducted the study selection. Disagreements between the investigators were resolved in meetings or adjudicated by a third reviewer (XS).

\section{Eligibility criteria}

The inclusion criteria were as follows: (1) population-rodent models with AKI; (2) intervention-various cell-derived EVs; (3) comparison-placebo; and (4) outcome measure-the primary outcome was the level of serum creatinine (Scr). The secondary outcomes were the renal injury score, percentage of

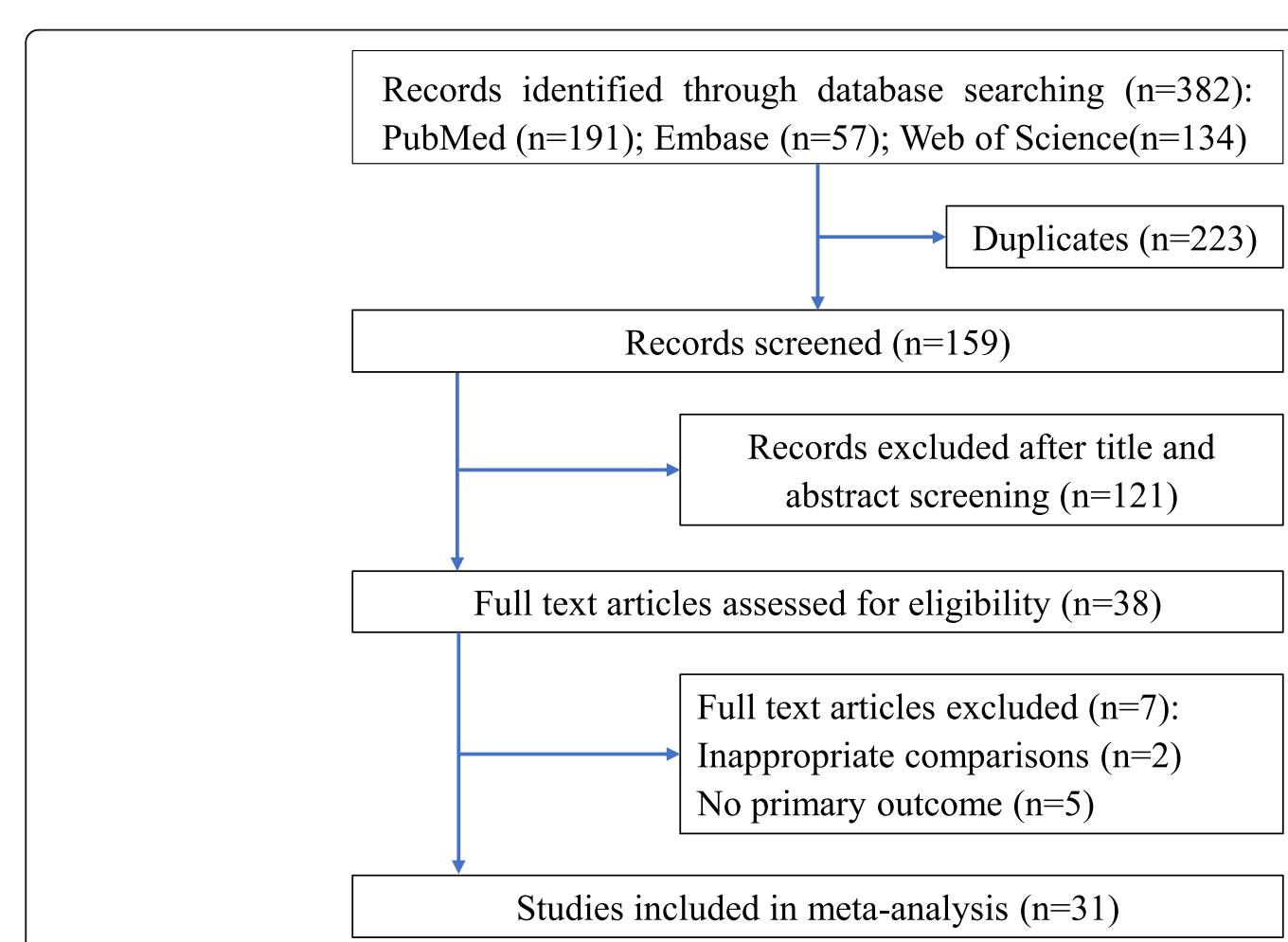

Fig. 1 Flow chart of the study selection 


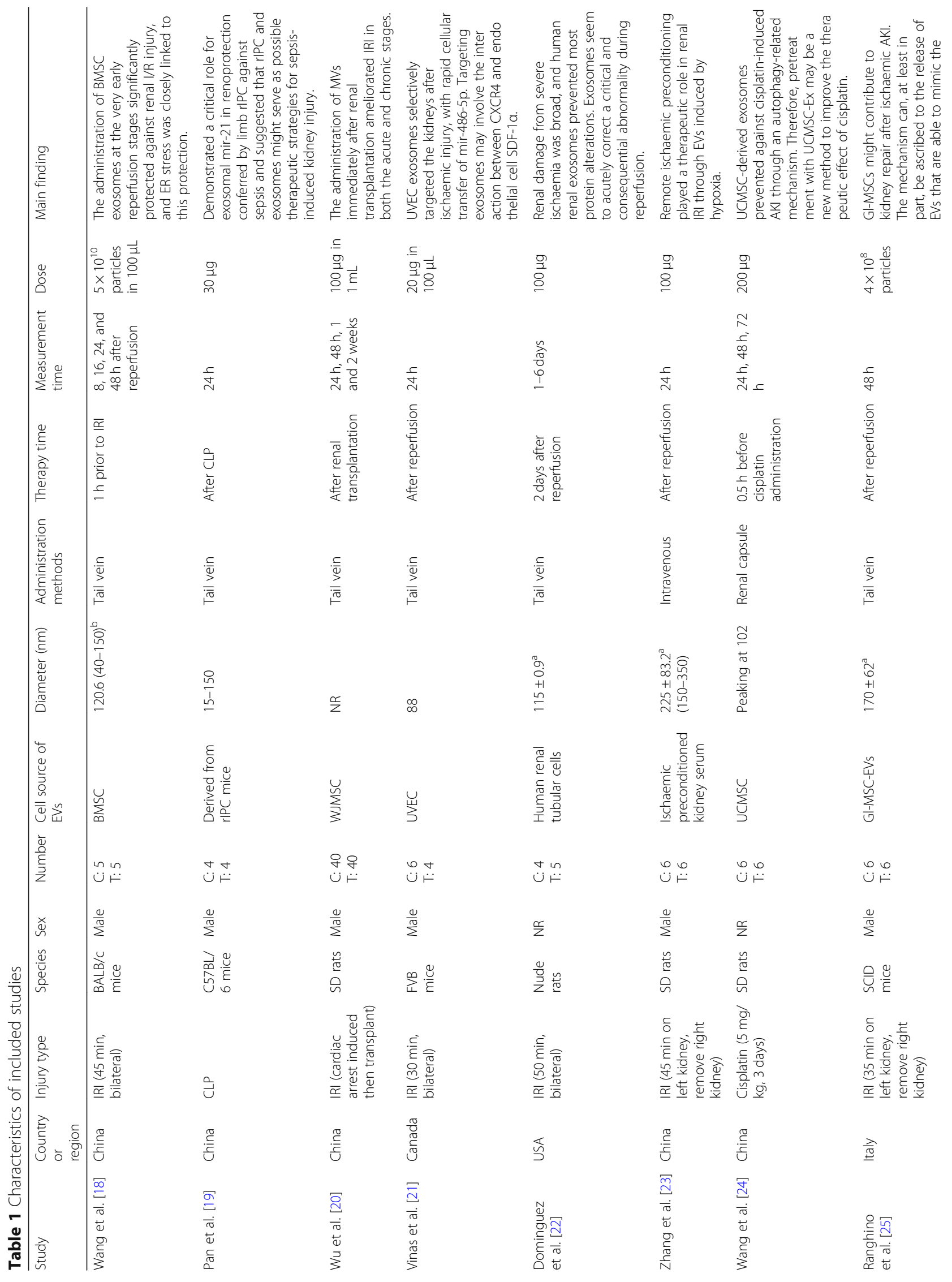




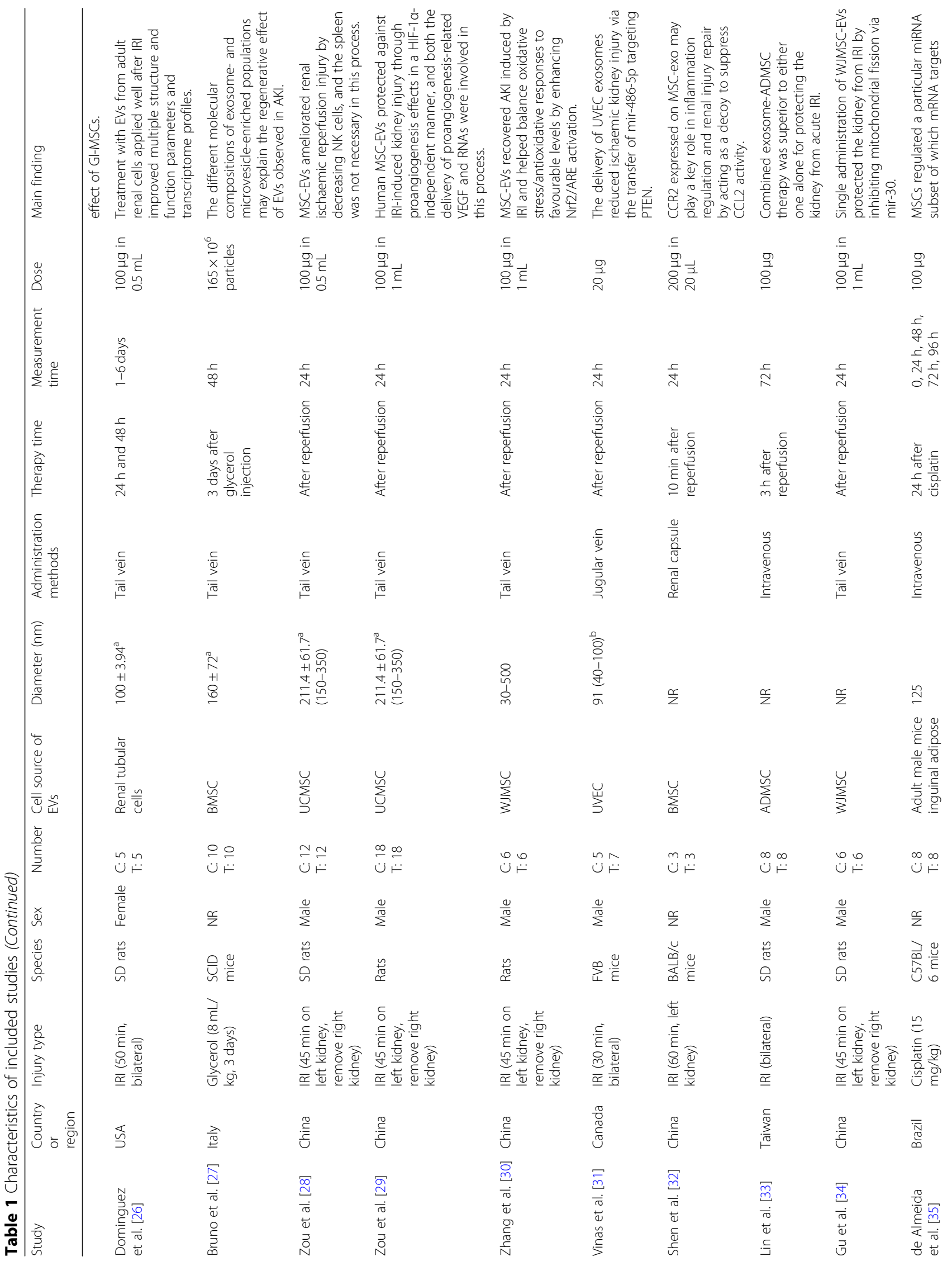




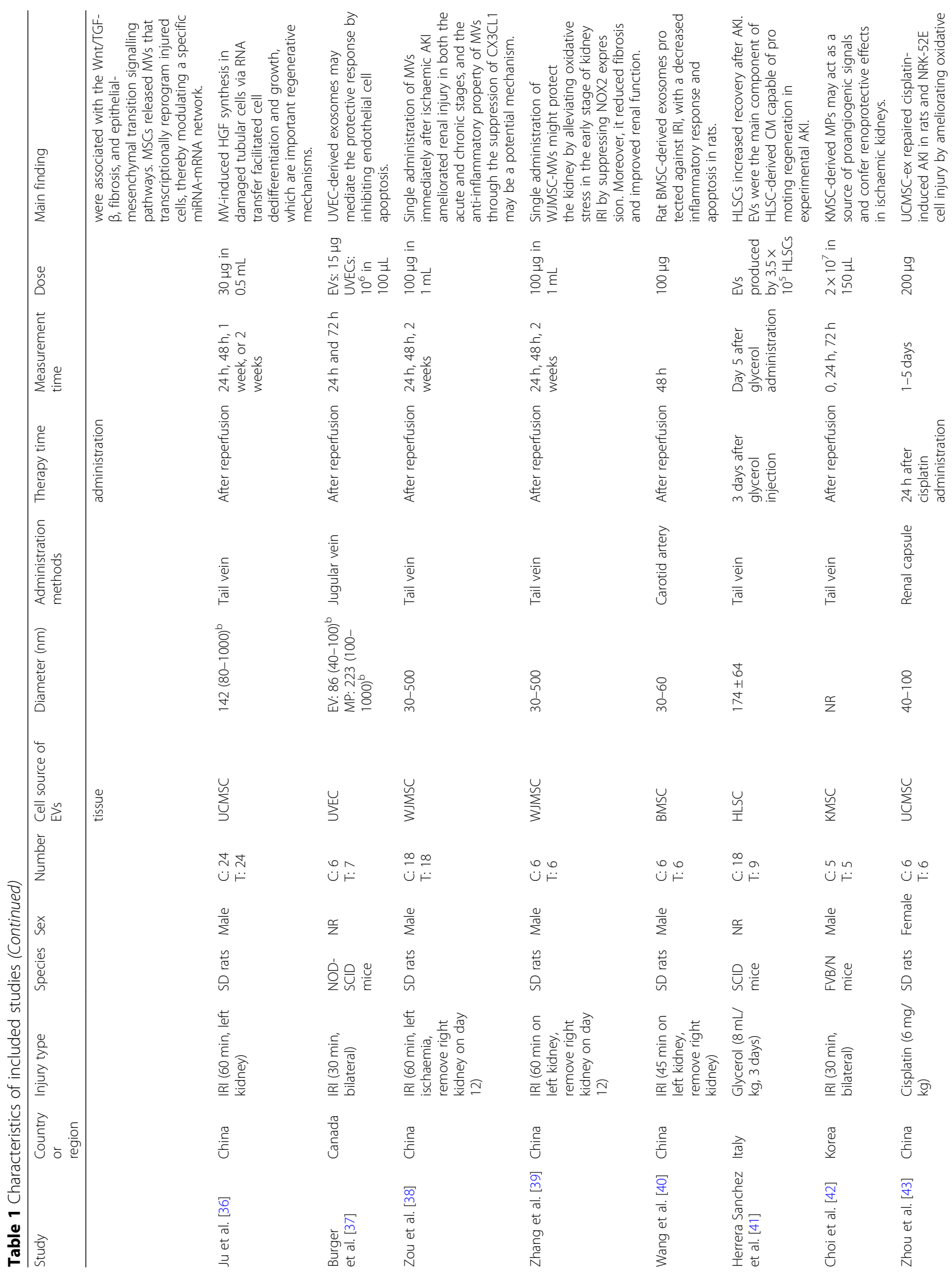




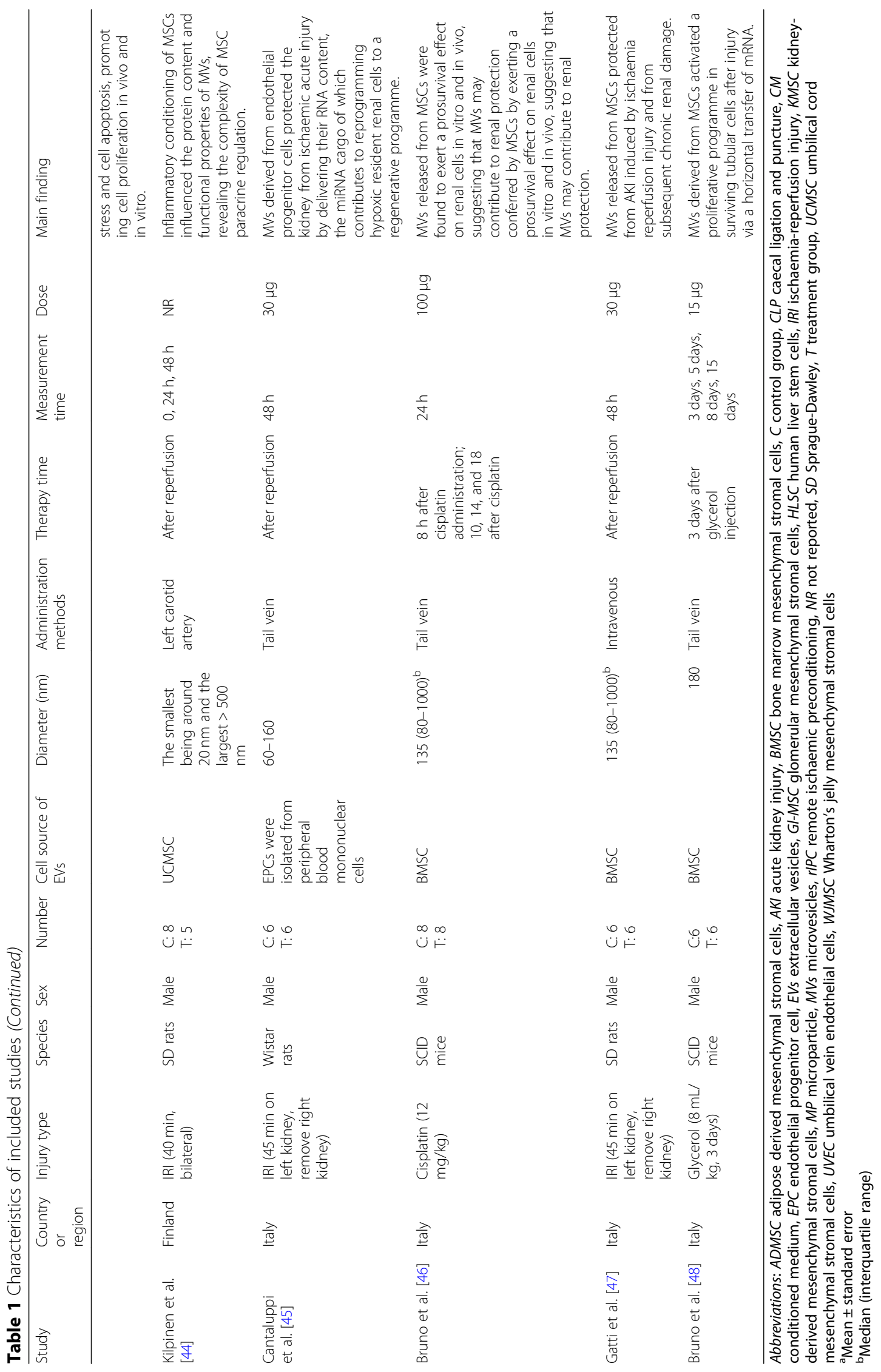


apoptotic cells, and levels of blood urea nitrogen (BUN), interleukin (IL)-10, and tumour necrosis factor (TNF)- $\alpha$.

The exclusion criteria were as follows: (1) AKI was not performed on rodent models, (2) repeated data, (3) insufficient information, and (4) review, letter, commentary, correspondence, case report, conference abstract, expert opinion, or editorial.

\section{Data extraction}

Data extraction was performed by two independent reviewers $(\mathrm{CL}$ and $\mathrm{JH})$ using a standardised form. The following data were collected: first author, country or region, publication year, number of animals, type of AKI model, species, treatment time, measurement time and EV cell origins, diameter, and dose. For studies that had not shown the corresponding results, Engauge Digitizer version 4.1 software was used to extract data from the graphics $[14,15]$.

\section{Quality assessment}

The methodological quality of each included study was evaluated by two independent authors (JW and ZM) with a Collaborative Approach to Meta-Analysis and Review of Animal Data from Experimental Studies (CAMARADES) 10-item checklist [16]: A, peerreviewed journal; $\mathrm{B}$, temperature control; $\mathrm{C}$, animals were randomly allocated; D, blind established model; E, blinded outcome assessment; F, use of anaesthetic without significant intrinsic vascular protection activity; G, appropriate animal model (diabetic, advanced age, or hypertensive); $\mathrm{H}$, calculation of the sample size; I, statement of compliance with animal welfare regulations; and J, statement of potential conflicts of interest.

\section{Statistical analysis}

All statistical analyses were conducted using RevMan version 5.3 and $R$ statistical software version 3.4.1. Statistical significance was set at $P<0.05$ (two-tailed). Continuous outcomes are expressed as the standardised mean difference (SMD) with the 95\% CI. Heterogeneity was analysed among studies using the $I^{2}$ statistic. $I^{2}>50 \%$ indicated significant heterogeneity [17]. Subgroup, sensitivity, and meta-regression analyses were performed to investigate potential betweenstudy heterogeneity and to explore other potentially confounding factors. A cumulative meta-analysis was performed to explore changes in the results over time. Funnel plots and Egger's test were conducted to detect publication bias. If publication bias was indicated, we further evaluated the number of missing studies by the Trimfill method and recalculated the pooled risk estimation with the addition of those missing studies.

\section{Results}

Search results and study characteristics

The process of study selection is outlined in Fig. 1. In total, 31 studies satisfied the inclusion criteria [18-48]. The main characteristics of the included studies are presented in Table 1. All these studies were published between 2009 and 2019, and a total of 552 rodent animals were included in this metaanalysis. Among the included studies, 8 used bone marrow mesenchymal stromal cell (BMSC)-EVs [18, 27, 32, 40, 46-48], 6 used human umbilical cord mesenchymal stromal cell (UCMSC)-EVs [24, 28, 29, 36, 43, 44], 4 used human umbilical Wharton's jelly mesenchymal stromal cell (WJMSC)-EVs [20, 30, 34, $38,39], 3$ used human umbilical vein endothelial cell (UVFC)-EVs [21, 31, 37], 2 used kidney-derived mesenchymal stromal cell (KMSC)-EVs [25, 42], 2 used adipose-derived mesenchymal stromal cell (ADMSC)EVs [33, 35], 1 used human liver stem cell (HLSC)EVs [41], and the 5 remaining used another origin of EVs [19, 22, 23, 26, 45]. The AKI model was established with IRI $[18,20-23,25,26,28-34,36-$ $40,42,44,45,47]$, cisplatin $[24,35,43,46]$, glycerol $[27,41,48]$, or the caecal ligation and puncture (CLP) method [19]. The diameter of the isolated EVs ranged from 15 to $1000 \mathrm{~nm}$ (mostly $50-200 \mathrm{~nm}$ ). Surface markers, including CD63, CD9, CD81, and tumour susceptibility gene (TSG) 101, were used to identify and sort EVs from other components. A variety of microRNAs have been reported in EVs, such as miR-21 [19], miR-451 [27], miR-486-5p [31], miR30 [34], and miR-199a-5p [18]. Most studies injected $100 \mu \mathrm{g}$ EVs intravenously after the injury model was established [20, 22, 23, 26, 28-30, 33-35, 38-40, 46] (Table 1).

\section{Quality assessment}

All the included records were peer-reviewed publications, and all animals were allocated randomly to a treatment group and a control group; however, most studies did not report sample size calculation, blinded induction of the model, or blinded assessment of outcome. The details of the study quality assessment are shown in Additional file 1: Table S1.

\section{Primary outcome}

All studies reported the level of Scr. The pooled analysis showed that EVs can significantly reduce the Scr level when compared with the control $\left(\mathrm{SMD}=-3.71 ; 95 \% \mathrm{CI}=-4.32,-3.10 ; P<0.01 ; I^{2}=\right.$ 


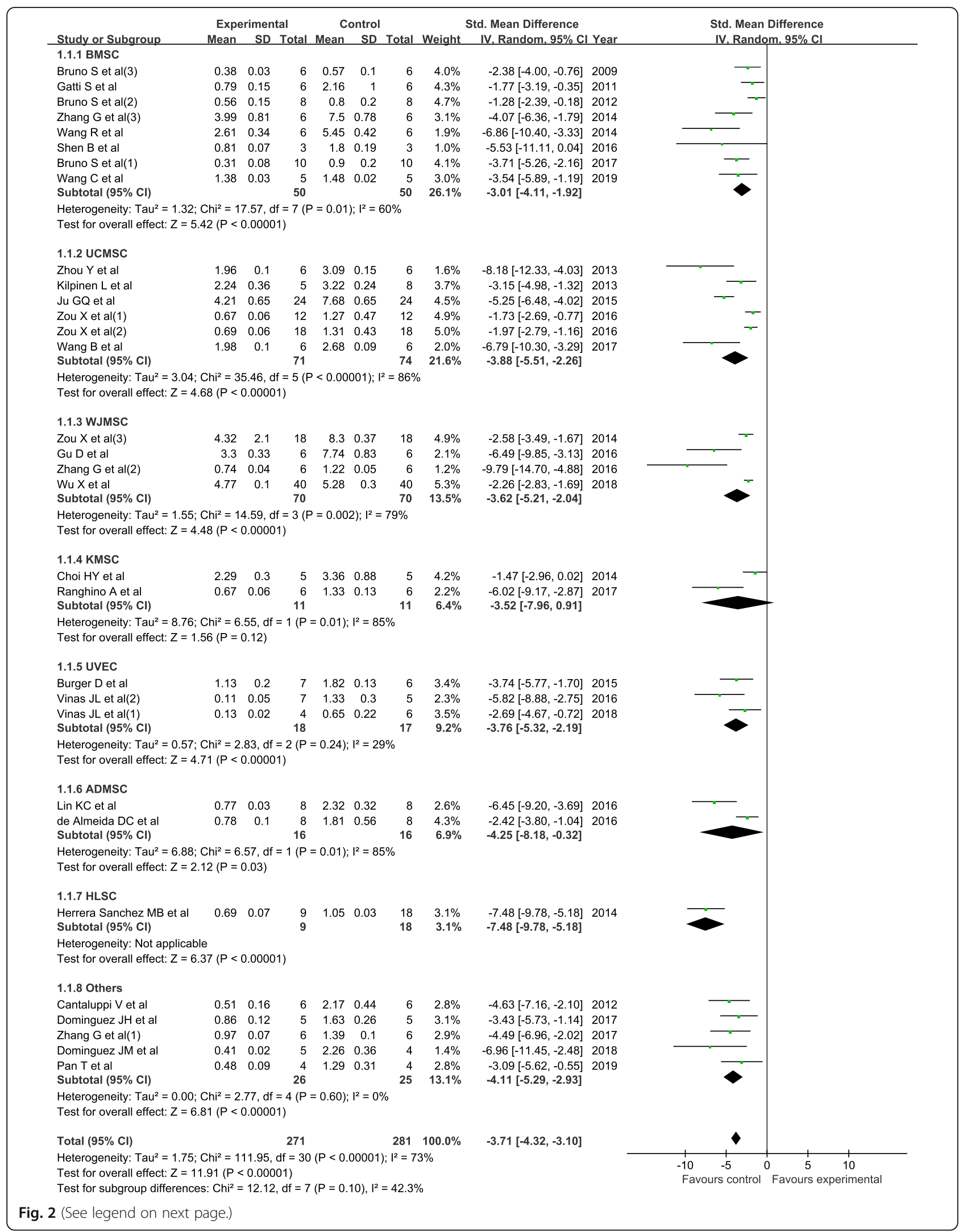


(See figure on previous page.)

Fig. 2 The forest plot shows the efficacy of EVs in reducing Scr levels in the AKI model. ADMSC, adipose-derived mesenchymal stromal cell; BMSC, bone marrow mesenchymal stromal cell; 95\% Cl, 95\% confidence interval; EVs, extracellular vesicles; HLSC, human liver stem cell; IV, inverse variance; KMSC, kidney-derived mesenchymal stromal cell; Scr, serum creatinine; SD, standard deviation; UCMSC, umbilical cord mesenchymal stromal cell; UVEC, umbilical vein endothelial cell; WJMSC, Wharton's jelly mesenchymal stromal cell

73\%; Fig. 2). The subgroup analysis showed that all cell-derived exosomes are effective in reducing the Scr level (Fig. 2). The cumulative meta-analysis showed that the result did not change over time (Additional file 2: Figure S1). The sensitivity analysis showed that none of the single studies significantly influenced the result (Additional file 3: Figure S2). The multivariable meta-regression analysis showed that the delivery dose $(P<0.05)$ and cell origin of EVs $(P<0.05)$ were independent influential factors of $\mathrm{SCr}$ reduction.

\section{Secondary outcomes}

The level of BUN was significantly decreased in the EV group $(\mathrm{SMD}=-3.68 ; \quad 95 \% \mathrm{CI}=-4.42, \quad-2.94$; $P<0.01 ; I^{2}=82 \%$; Fig. 3 ). A subgroup analysis was performed according to the origin of the EVs, and the results indicated that all kinds of EVs included in this meta-analysis would reduce the level of BUN. The cumulative meta-analysis showed that the result did not change over time (Additional file 4: Figure S3). The sensitivity analysis showed that none of the single studies significantly influenced the result (Additional file 5: Figure S4). The meta-regression analysis showed that the cell origin of the EVs $(P<$ 0.05) was an independent influential factor of BUN reduction.

Other secondary outcomes are summarised in Table 2. TUNEL assays were carried out in kidney tissue to detect apoptotic cells. Ten studies [20, 24, 30, 31, 34, 36, 38-40, 45] reported TUNEL results, and the pooled analysis showed that EVs can significantly reduce cell apoptosis. The tubular injury score was reported in six studies [21, 23, 30, 31, 33, 37], and the results showed that the injury score was lower in the EV group. In the EV group, the anti-inflammatory cytokine IL-10 [20, 24, 38 ] was significantly increased and the proinflammatory cytokine TNF- $\alpha[20,35,38]$ was significantly decreased (Table 2).

Among the included studies, seven compared the efficacy of cell-derived EVs with cells in the AKI model. The results showed no significant difference in Scr $\left(\mathrm{SMD}=0.29 ; 95 \% \mathrm{CI}=-0.66,1.24 ; P=0.55 ; I^{2}=\right.$ $74 \%$; Fig. 4a) or BUN (SMD $=-0.50 ; 95 \% \mathrm{CI}=-0.17$, 1.18; $P=0.15 ; I^{2}=45 \%$; Fig. 4b) levels between the two groups. Meanwhile, no significant difference was found between stem cell-derived EVs and stem cells (Fig. 4).

\section{Publication bias}

Significant publication bias was observed $(P<0.01$; Additional file 6: Figure S5). We used the Trimfill method to recalculate the pooled risk estimation with the addition of missing studies (Additional file 7: Figure S6). However, the overall results were not significantly changed. Therefore, publication bias may have little effect on the meta-analysis outcomes (data not shown).

\section{Discussion}

Our meta-analysis of 31 studies provided a comprehensive summary of the effect of EVs on the preclinical rodent AKI model. Pooled analyses confirmed that EV therapy could improve renal function and the inflammatory response status and reduce cell apoptosis in a preclinical rodent AKI model. The multivariable meta-regression analysis indicated that the delivery dose and cell origin of EVs were independent factors influencing the effect of EVs. Meanwhile, no significant difference was found between stem cellderived EVs and stem cells. Therefore, the present meta-analysis provides important clues for human clinical trials on EVs.

A previous meta-analysis focused on this topic indicated that mesenchymal stromal cell-derived EVs produce a more marked therapeutic effect on recovery from renal failure than MSC-conditioned medium [49]. Our meta-analysis contained various types of cell-derived EVs and further evaluated the effect of EVs on cell apoptosis, the tubular injury score, and inflammatory cytokines, providing useful information for further clinical trials.

Many studies have shown that RNAs carried by EVs are the pivotal mechanism for their therapeutic function $[11,50]$, and the proteins contained in EVs are also related to many biological processes. EVs are membrane-bound vesicles released by all cell types, including stem/progenitor cells, which are important information carriers for regulating angiogenesis, extracellular matrix remodelling, gene expression, inflammation states, the cell cycle and proliferation, the phenotype of target cells, cell migration, and morphogenesis [51-54]. The surface 


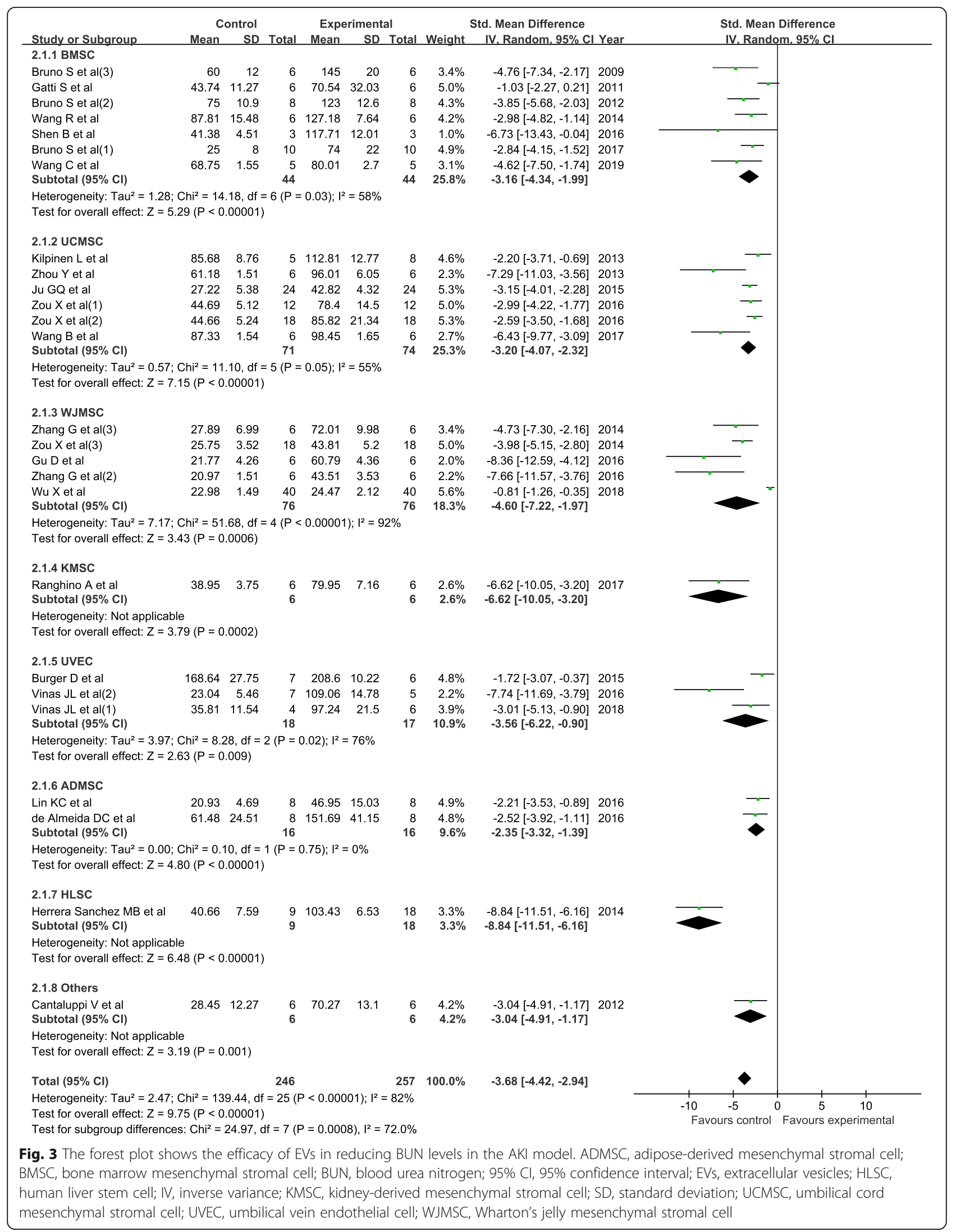


Table 2 Secondary outcomes

\begin{tabular}{llccc}
\hline Outcomes & Number of studies & Std. mean difference $(95 \% \mathrm{Cl})$ & Test for effect $(P$ value $)$ & Heterogeneity, $I^{2}(P$ value $)$ \\
\hline TUNEL & $10[20,24,30,31,34,36,38-40,45]$ & $-6.25(-8.10,-4.39)$ & $<0.01$ & $87 \%(<0.01)$ \\
Injury score & $6[21,23,30,31,33,37]$ & $-3.90(-5.26,-2.53)$ & $<0.01$ & $54 \%(0.05)$ \\
IL-10 & $3[20,24,38]$ & $2.10(1.18,3.02)$ & $<0.01$ & $68 \%(0.04)$ \\
TNF-a & $3[20,35,38]$ & $-2.65(-4.98,-0.32)$ & 0.03 & $95 \%(<0.01)$ \\
\hline
\end{tabular}

Abbreviations: IL interleukin, TNF tumour necrosis factor

molecules of EVs permit them to be targeted to recipient cells. Once attached to a target cell, EVs can induce signalling via a receptor-ligand interaction, be internalised by endocytosis and/or phagocytosis, or even fuse with the target cell's membrane to deliver their content into its cytosol, thereby modifying the physiological state of the recipient cell $[55,56]$.

Compared with stem cells, stem cell-derived EVs have lower immunogenicity and may reduce some of the risks associated with cellular therapy, such as cytokine release syndrome [51]. In our metaanalysis, we demonstrated that stem cell-derived EVs were equally effective as stem cells when applied to treat AKI. In one study, MSC-derived EVs were superior to MSCs in reducing global renal damage levels in a rat model of donation after circulatory death (DCD) kidney [57]. Thus, EVs appear to be a promising approach for the repair of AKI.

The multivariable meta-regression analysis showed that the delivery dose and cell origin of EVs were independent factors influencing the efficacy of EVs. This suggests that we need to consider these factors when performing clinical trials. The properties and cargoes of EVs have been summarised in databases that are continuously updated, namely, Vesiclepedia, ExoCarta, and EVpedia [58]. Interestingly, the same cell may release EVs that differ in the content of their membrane lipid composition and in their intravesicular cargo [58, 59]. Therefore, further studies are urgently needed to explore the mechanism behind this phenomenon.

In our meta-analysis, various sizes of EVs were included. The large heterogeneity between EVs poses major obstacles to understanding the composition and functional properties of distinct secreted components [60]. One recent research reassessment of exosome composition established the differential distribution of protein, RNA, and DNA between small EVs and nonvesicular extracellular matter and demonstrated that small EVs are not vehicles of active DNA release [60]. It is important for further study to identify the key elements in AKI treatment.
One clinical trial tested the effects of MSC-derived EVs on the progression of chronic kidney disease (CKD) patients, and the results indicated that EVs can improve the estimated glomerular filtration rate (eGFR); decrease Scr, BUN, and TNF- $\alpha$ levels; and increase IL-10 levels [61]. However, significant translational challenges need to be addressed before the use of MSC-derived EVs for the clinical treatment of AKI. First, EV isolation and storage methods may potentially affect EV characteristics. It is challenging to ensure that recovered vesicles are truly from the extracellular space rather than from intracellular vesicles or artefactual particles released from cells broken during tissue harvest, processing (e.g. mechanical disruption), or storage (including freezing) [9]. Second, in most studies, the follow-up time ranged from 1 day to 2 weeks. Therefore, the long-term effects of EVs are a key issue that requires further exploration before their clinical application. Third, a development method that can be used to meet the large-scale clinical production requirement of a sufficient quantity of EVs is also a core problem [51]. Fourth, labelling EVs with lipophilic or surfacecoating fluorophores may modify the physicochemical characteristics of EVs and alter the detection mode and/or uptake by target cells [9]; thus, the development of specific tracking tools is required to further detect EVs.

\section{Limitations}

Several potential limitations to this meta-analysis should be considered. First, despite the fact that we performed subgroup and sensitivity analyses, the heterogeneity between studies cannot be remarkably reduced. This may weaken the stability of the results. Second, we included stem cell-derived EVs and other cell origin EVs, but we did not perform a direct comparison to identify the best option, which may have also increased the heterogeneity. Third, there was potential for the incomplete retrieval of identified research studies, which could have introduced publication bias. Finally, data extraction from graphics by using Engauge Digitizer software may have altered the original data, which would also affect the results. 


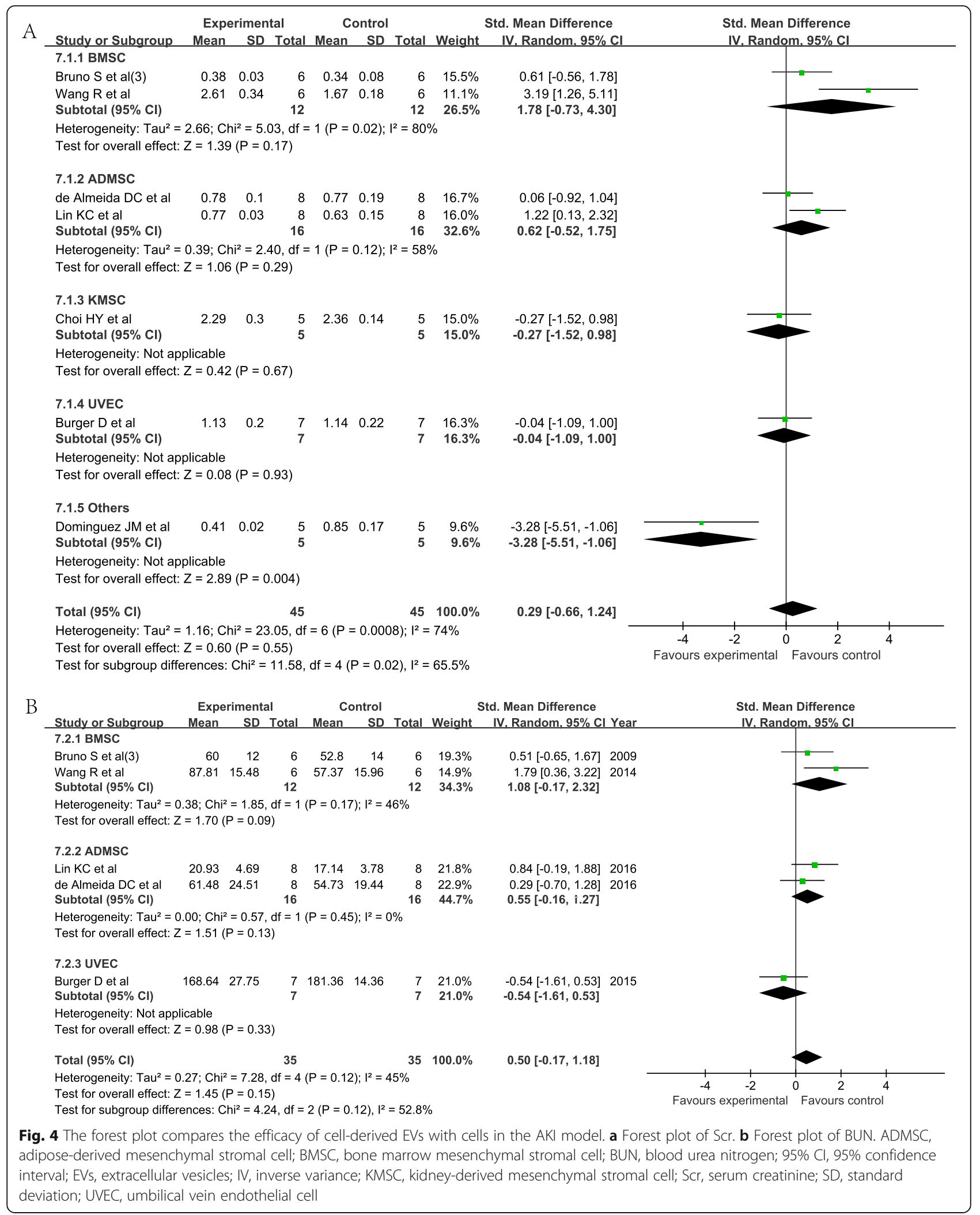




\section{Conclusion}

The present meta-analysis confirmed that EV therapy could improve renal function and the inflammatory response status and reduce cell apoptosis in a preclinical rodent AKI model. This provides important clues for human clinical trials on EVs.

\section{Supplementary information}

Supplementary information accompanies this paper at https://doi.org/10. 1186/s13287-019-1530-4

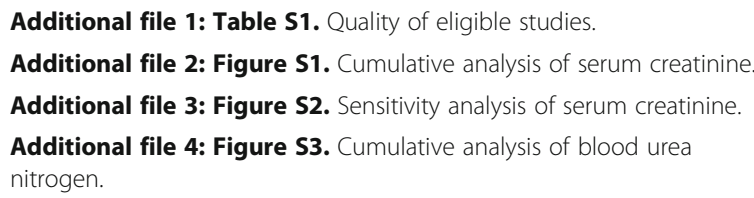

Additional file 5: Figure S4. Sensitivity analysis of blood urea nitrogen. Additional file 6: Figure S5. Funnel plot of publication bias.

Additional file 7: Figure S6. Funnel plot of publication bias according to the Trimfill method.

\section{Abbreviations}

ADMSC: Adipose-derived mesenchymal stromal cell; AKI: Acute kidney injury; BMSC: Bone marrow mesenchymal stromal cell; BUN: Blood urea nitrogen; CM: Conditioned medium; EPC: Endothelial progenitor cell; EVs: Extracellular vesicles; HLSC: Human liver stem cell; IRI: Ischaemia-reperfusion injury; KMSC: Kidney-derived mesenchymal stromal cell; Scr: Serum creatinine; UCMSC: Umbilical cord mesenchymal stromal cell; UVEC: Umbilical vein endothelial cell; WJMSC: Wharton's jelly mesenchymal stromal cell

\section{Acknowledgements}

Not applicable.

\section{Authors' contributions}

$\mathrm{CL}, \mathrm{JW}$, and $\mathrm{JH}$ conceived the study, participated in the design, collected the data, performed the statistical analyses, and drafted the manuscript. BF, ZM, and HDZ performed the statistical analyses and helped draft the manuscript. GYC and XMC critically revised the manuscript for important intellectual content. FHZ collected the data, performed the statistical analyses, and helped revise the manuscript critically for important intellectual content. All authors read and approved the final manuscript.

\section{Funding}

This study was supported by a grant from the National Natural Science Foundation of China (81870463)

\section{Availability of data and materials}

The authors confirm that all data underlying the findings are fully available without restriction. All relevant data are provided in the paper and its Additional files.

\section{Ethics approval and consent to participate}

Not applicable.

\section{Consent for publication}

Not applicable.

\section{Competing interests}

The authors declare that they have no competing interests.

\section{Author details}

'Department of Nephrology, Chinese PLA General Hospital, Chinese PLA Institute of Nephrology, State Key Laboratory of Kidney Diseases, National Clinical Research Center for Kidney Diseases, 28 Fuxing Road, Beijing, China ${ }^{2}$ Department of Critical Care Medicine, Chinese PLA General Hospital, 28
Fuxing Road, Beijing, China. ${ }^{3}$ Master Program of Medical Science in Clinical Investigation, Harvard Medical School, 25 Shattuck Street, Boston, MA, USA

Received: 15 August 2019 Revised: 16 September 2019

Accepted: 23 September 2019

\section{References}

1. Shu S, Wang Y, Zheng M, Liu Z, Cai J, Tang C, Dong Z. Hypoxia and Hypoxia-Inducible Factors in Kidney Injury and Repair. Cells. 2019;8(3):207.

2. Patschan D, Buschmann I, Ritter O, Kribben A. Cell-based therapies in acute kidney injury (AKI). Kidney Blood Press Res. 2018;43(3):673-81.

3. Farzamfar S, Hasanpour A, Nazeri N, Razavi H, Salehi M, Shafei S, Nooshabadi VT, Vaez A, Ehterami A, Sahrapeyma H, et al. Extracellular micro/nanovesicles rescue kidney from ischemia-reperfusion injury. J Cell Physiol. 2019;234(8): 12290-300

4. Hu J, Zhang L, Wang N, Ding R, Cui S, Zhu F, Xie Y, Sun X, Wu D, Hong Q, et al. Mesenchymal stem cells attenuate ischemic acute kidney injury by inducing regulatory $T$ cells through splenocyte interactions. Kidney Int. 2013;84(3):521-31.

5. Geng X, Hong Q, Wang W, Zheng W, Li O, Cai G, Chen X, Wu D. Biological membrane-packed mesenchymal stem cells treat acute kidney disease by ameliorating mitochondrial-related apoptosis. Sci Rep. 2017:7:41136.

6. Yun CW, Lee SH. Potential and Therapeutic Efficacy of Cell-based Therapy Using Mesenchymal Stem Cells for Acute/chronic Kidney Disease. Int J Mol Sci. 2019;20(7):1619.

7. Caldas HC, Lojudice FH, Dias C, Fernandes-Charpiot IMM, Baptista M, Kawasaki-Oyama RS, Sogayar MC, Takiya CM, Abbud-Filho M. Induced pluripotent stem cells reduce progression of experimental chronic kidney disease but develop Wilms' tumors. Stem Cells Int. 2017;2017:7428316.

8. Wang SY, Hong Q, Zhang CY, Yang YJ, Cai GY, Chen XM. miRNAs in stem cell-derived extracellular vesicles for acute kidney injury treatment: comprehensive review of preclinical studies. Stem Cell Res Ther. 2019;10(1): 281.

9. Thery C, Witwer KW, Aikawa E, Alcaraz MJ, Anderson JD, Andriantsitohaina $\mathrm{R}$, Antoniou A, Arab T, Archer F, Atkin-Smith GK, et al. Minimal information for studies of extracellular vesicles 2018 (MISEV2018): a position statement of the International Society for Extracellular Vesicles and update of the MISEV2014 guidelines. J Extracell Vesicles. 2018;7(1):1535750.

10. Stahl AL, Johansson K, Mossberg M, Kahn R, Karpman D. Exosomes and microvesicles in normal physiology, pathophysiology, and renal diseases. Pediatr Nephrol. 2019;34(1):11-30.

11. Grange C, lampietro C, Bussolati B. Stem cell extracellular vesicles and kidney injury. Stem Cell Investig. 2017;4:90

12. Aghajani Nargesi A, Lerman LO, Eirin A. Mesenchymal stem cell-derived extracellular vesicles for kidney repair: current status and looming challenges. Stem Cell Res Ther. 2017;8(1):273.

13. Moher D, Liberati A, Tetzlaff J, Altman DG, Group P. Preferred reporting items for systematic reviews and meta-analyses: the PRISMA statement. BMJ. 2009:339:b2535.

14. Tierney JF, Stewart LA, Ghersi D, Burdett S, Sydes MR. Practical methods for incorporating summary time-to-event data into meta-analysis. Trials. 2007:8:16.

15. Wu XL, Tu Q, Faure G, Gallet P, Kohler C, Bittencourt Mde C. Diagnostic and prognostic value of circulating tumor cells in head and neck squamous cell carcinoma: a systematic review and meta-analysis. Sci Rep. 2016;6:20210.

16. Macleod MR, O'Collins T, Howells DW, Donnan GA. Pooling of animal experimental data reveals influence of study design and publication bias. Stroke. 2004;35(5):1203-8.

17. Higgins JP, Thompson SG, Deeks JJ, Altman DG. Measuring inconsistency in meta-analyses. BMJ. 2003;327(7414):557-60.

18. Wang C, Zhu G, He W, Yin H, Lin F, Gou X, Li X: BMSCs protect against renal ischemia-reperfusion injury by secreting exosomes loaded with miR-199a-5p that target BIP to inhibit endoplasmic reticulum stress at the very early reperfusion stages. FASEB J 2019:fj201801821R.

19. Pan $T$, Jia $P$, Chen N, Fang $Y$, Liang $Y$, Guo M, Ding $X$. Delayed remote ischemic preconditioning confersrenoprotection against septic acute kidney injury via exosomal miR-21. Theranostics. 2019;9(2):405-23.

20. Wu X, Yan T, Wang Z, Wu X, Cao G, Zhang C, Tian X, Wang J. Micro-vesicles derived from human Wharton's jelly mesenchymal stromal cells mitigate renal ischemia-reperfusion injury in rats after cardiac death renal transplantation. J Cell Biochem. 2018;119(2):1879-88. 
21. Vinas JL, Spence M, Gutsol A, Knoll W, Burger D, Zimpelmann J, Allan DS, Burns KD. Receptor-ligand interaction mediates targeting of endothelial colony forming cell-derived exosomes to the kidney after ischemic injury. Sci Rep. 2018;8(1):16320.

22. Dominguez JM 2nd, Dominguez JH, Xie D, Kelly KJ. Human extracellular microvesicles from renal tubules reverse kidney ischemia-reperfusion injury in rats. PLoS One. 2018;13(8):e0202550.

23. Zhang G, Yang Y, Huang Y, Zhang L, Ling Z, Zhu Y, Wang F, Zou X, Chen M. Hypoxia-induced extracellular vesicles mediate protection of remote ischemic preconditioning for renal ischemia-reperfusion injury. Biomed Pharmacother. 2017:90:473-8.

24. Wang B, Jia H, Zhang B, Wang J, Ji C, Zhu X, Yan Y, Yin L, Yu J, Qian H, et al. Pre-incubation with hucMSC-exosomes prevents cisplatin-induced nephrotoxicity by activating autophagy. Stem Cell Res Ther. 2017:8(1):75

25. Ranghino A, Bruno S, Bussolati B, Moggio A, Dimuccio V, Tapparo M, Biancone L, Gontero P, Frea B, Camussi G. The effects of glomerular and tubular renal progenitors and derived extracellular vesicles on recovery from acute kidney injury. Stem Cell Res Ther. 2017;8(1):24.

26. Dominguez JH, Liu Y, Gao H, Dominguez JM 2nd, Xie D, Kelly KJ. Renal tubular cell-derived extracellular vesicles accelerate the recovery of established renal ischemia reperfusion injury. J Am Soc Nephrol. 2017;28(12): 3533-44.

27. Bruno S, Tapparo M, Collino F, Chiabotto G, Deregibus MC, Soares Lindoso R, Neri F, Kholia S, Giunti S, Wen S, et al. Renal regenerative potential of different extracellular vesicle populations derived from bone marrow mesenchymal stromal cells. Tissue Eng Part A. 2017;23(21-22):1262-73.

28. Zou X, Gu D, Zhang G, Zhong L, Cheng Z, Liu G, Zhu Y. NK cell regulatory property is involved in the protective role of MSC-derived extracellular vesicles in renal ischemic reperfusion injury. Hum Gene Ther. 2016;27(11): 926-35

29. Zou X, Gu D, Xing X, Cheng Z, Gong D, Zhang G, Zhu Y. Human mesenchymal stromal cell-derived extracellular vesicles alleviate renal ischemic reperfusion injury and enhance angiogenesis in rats. Am J Transl Res. 2016:8(10):4289-99.

30. Zhang G, Zou X, Huang Y, Wang F, Miao S, Liu G, Chen M, Zhu Y. Mesenchymal stromal cell-derived extracellular vesicles protect against acute kidney injury through anti-oxidation by enhancing Nrf2/ARE activation in rats. Kidney Blood Press Res. 2016;41(2):119-28.

31. Vinas JL, Burger D, Zimpelmann J, Haneef R, Knoll W, Campbell P, Gutsol A, Carter A, Allan DS, Burns KD. Transfer of microRNA-486-5p from human endothelial colony forming cell-derived exosomes reduces ischemic kidney injury. Kidney Int. 2016;90(6):1238-50.

32. Shen B, Liu J, Zhang F, Wang Y, Qin Y, Zhou Z, Qiu J, Fan Y. CCR2 positive exosome released by mesenchymal stem cells suppresses macrophage functions and alleviates ischemia/reperfusion-induced renal injury. Stem Cells Int. 2016;2016:1240301.

33. Lin KC, Yip HK, Shao PL, Wu SC, Chen KH, Chen YT, Yang CC, Sun CK, Kao GS, Chen SY, et al. Combination of adipose-derived mesenchymal stem cells (ADMSC) and ADMSC-derived exosomes for protecting kidney from acute ischemia-reperfusion injury. Int J Cardiol. 2016;216:173-85.

34. Gu D, Zou X, Ju G, Zhang G, Bao E, Zhu Y. Mesenchymal stromal cells derived extracellular vesicles ameliorate acute renal ischemia reperfusion injury by inhibition of mitochondrial fission through miR-30. Stem Cells Int 2016;2016:2093940.

35. de Almeida DC, Bassi EJ, Azevedo H, Anderson L, Origassa CS, Cenedeze MA, de Andrade-Oliveira V, Felizardo RJ, da Silva RC, Hiyane MI, et al. A regulatory miRNA-mRNA network is associated with tissue repair induced by mesenchymal stromal cells in acute kidney injury. Front Immunol. 2016;7:645

36. Ju GQ, Cheng J, Zhong L, Wu S, Zou XY, Zhang GY, Gu D, Miao S, Zhu YJ, Sun J, et al. Microvesicles derived from human umbilical cord mesenchymal stem cells facilitate tubular epithelial cell dedifferentiation and growth via hepatocyte growth factor induction. PLoS One. 2015;10(3):e0121534.

37. Burger D, Vinas JL, Akbari S, Dehak H, Knoll W, Gutsol A, Carter A, Touyz RM, Allan DS, Burns KD. Human endothelial colony-forming cells protect against acute kidney injury: role of exosomes. Am J Pathol. 2015;185(8):2309-23.

38. Zou X, Zhang G, Cheng Z, Yin D, Du T, Ju G, Miao S, Liu G, Lu M, Zhu Y. Microvesicles derived from human Wharton's jelly mesenchymal stromal cells ameliorate renal ischemia-reperfusion injury in rats by suppressing CX3CL1. Stem Cell Res Ther. 2014;5(2):40.

39. Zhang G, Zou X, Miao S, Chen J, Du T, Zhong L, Ju G, Liu G, Zhu Y. The anti-oxidative role of micro-vesicles derived from human Wharton-jelly mesenchymal stromal cells through NOX2/gp91(phox) suppression in alleviating renal ischemia-reperfusion injury in rats. PLoS One. 2014;9(3): e92129.

40. Wang $R$, Lin $M$, Li L, Li L, Qi G, Rong R, Xu M, Zhu T. Bone marrow mesenchymal stem cell-derived exosome protects kidney against ischemia reperfusion injury in rats. Zhonghua Yi Xue Za Zhi. 2014; 94(42):3298-303.

41. Herrera Sanchez MB, Bruno S, Grange C, Tapparo M, Cantaluppi V, Tetta C, Camussi G. Human liver stem cells and derived extracellular vesicles improve recovery in a murine model of acute kidney injury. Stem Cell Res Ther. 2014;5(6):124.

42. Choi HY, Moon SJ, Ratliff BB, Ahn SH, Jung A, Lee M, Lee S, Lim BJ, Kim BS, Plotkin MD, et al. Microparticles from kidney-derived mesenchymal stem cells act as carriers of proangiogenic signals and contribute to recovery from acute kidney injury. PLoS One. 2014;9(2):e87853.

43. Zhou Y, Xu H, Xu W, Wang B, Wu H, Tao Y, Zhang B, Wang M, Mao F, Yan Y, et al. Exosomes released by human umbilical cord mesenchymal stem cells protect against cisplatin-induced renal oxidative stress and apoptosis in vivo and in vitro. Stem Cell Res Ther. 2013;4(2):34.

44. Kilpinen L, Impola U, Sankkila L, Ritamo I, Aatonen M, Kilpinen S, Tuimala J, Valmu L, Levijoki J, Finckenberg P, et al. Extracellular membrane vesicles from umbilical cord blood-derived MSC protect against ischemic acute kidney injury, a feature that is lost after inflammatory conditioning. J Extracell Vesicles. 2013;2:21927.

45. Cantaluppi V, Gatti S, Medica D, Figliolini F, Bruno S, Deregibus MC, Sordi A, Biancone L, Tetta C, Camussi G. Microvesicles derived from endothelial progenitor cells protect the kidney from ischemia-reperfusion injury by microRNA-dependent reprogramming of resident renal cells. Kidney Int. 2012;82(4):412-27

46. Bruno S, Grange C, Collino F, Deregibus MC, Cantaluppi V, Biancone L, Tetta C, Camussi G. Microvesicles derived from mesenchymal stem cells enhance survival in a lethal model of acute kidney injury. PLoS One. 2012;7(3):e33115.

47. Gatti S, Bruno S, Deregibus MC, Sordi A, Cantaluppi V, Tetta C, Camussi G. Microvesicles derived from human adult mesenchymal stem cells protect against ischaemia-reperfusion-induced acute and chronic kidney injury. Nephrol Dial Transplant. 2011;26(5):1474-83.

48. Bruno S, Grange C, Deregibus MC, Calogero RA, Saviozzi S, Collino F, Morando L, Busca A, Falda M, Bussolati B, et al. Mesenchymal stem cellderived microvesicles protect against acute tubular injury. J Am Soc Nephrol. 2009;20(5):1053-67.

49. Zhang G, Wang D, Miao S, Zou X, Liu G, Zhu Y. Extracellular vesicles derived from mesenchymal stromal cells may possess increased therapeutic potential for acute kidney injury compared with conditioned medium in rodent models: a meta-analysis. Exp Ther Med. 2016;11(4):1519-25.

50. Nargesi AA, Lerman LO, Eirin A. Mesenchymal stem cell-derived extracellular vesicles for renal repair. Curr Gene Ther. 2017;17(1):29-42.

51. Sun X, Meng H, Wan W, Xie M, Wen C. Application potential of stem/ progenitor cell-derived extracellular vesicles in renal diseases. Stem Cell Res Ther. 2019;10(1):8

52. Eirin A, Zhu XY, Puranik AS, Woollard JR, Tang H, Dasari S, Lerman A, van Wijnen AJ, Lerman LO. Comparative proteomic analysis of extracellular vesicles isolated from porcine adipose tissue-derived mesenchymal stem/ stromal cells. Sci Rep. 2016:6:36120.

53. Anderson JD, Johansson HJ, Graham CS, Vesterlund M, Pham MT, Bramlett CS, Montgomery EN, Mellema MS, Bardini RL, Contreras Z, et al. Comprehensive proteomic analysis of mesenchymal stem cell exosomes reveals modulation of angiogenesis via nuclear factor-kappaB signaling. Stem Cells. 2016:34(3):601-13.

54. Zhou Y, Li P, Goodwin AJ, Cook JA, Halushka PV, Chang E, Zingarelli B, Fan $H$. Exosomes from endothelial progenitor cells improve outcomes of the lipopolysaccharide-induced acute lung injury. Crit Care. 2019;23(1):44.

55. Tkach $\mathrm{M}$, Thery C. Communication by extracellular vesicles: where we are and where we need to go. Cell. 2016;164(6):1226-32.

56. Real JM, Ferreira LRP, Esteves GH, Koyama FC, Dias MVS, Bezerra-Neto JE, Cunha-Neto E, Machado FR, Salomao R, Azevedo LCP. Exosomes from patients with septic shock convey miRNAs related to inflammation and cell cycle regulation: new signaling pathways in sepsis? Crit Care. 2018;22(1):68.

57. Gregorini M, Corradetti V, Pattonieri EF, Rocca C, Milanesi S, Peloso A, Canevari S, De Cecco L, Dugo M, Avanzini MA, et al. Perfusion of isolated rat kidney with mesenchymal stromal cells/extracellular vesicles prevents ischaemic injury. J Cell Mol Med. 2017;21(12):3381-93. 
58. Karpman D, Stahl AL, Arvidsson I. Extracellular vesicles in renal disease. Nat Rev Nephrol. 2017;13(9):545-62

59. Lai RC, Tan SS, Yeo RW, Choo AB, Reiner AT, Su Y, Shen Y, Fu Z, Alexander L, Sze SK, et al. MSC secretes at least $3 \mathrm{EV}$ types each with a unique permutation of membrane lipid, protein and RNA. J Extracell Vesicles. 2016; 5:29828.

60. Jeppesen DK, Fenix AM, Franklin JL, Higginbotham JN, Zhang Q Zimmerman $\sqcup$, Liebler DC, Ping J, Liu Q, Evans R, et al. Reassessment of exosome composition. Cell. 2019;177(2):428-45 e418.

61. Nassar W, El-Ansary M, Sabry D, Mostafa MA, Fayad T, Kotb E, Temraz M, Saad AN, Essa W, Adel H. Umbilical cord mesenchymal stem cells derived extracellular vesicles can safely ameliorate the progression of chronic kidney diseases. Biomater Res. 2016;20:21.

\section{Publisher's Note}

Springer Nature remains neutral with regard to jurisdictional claims in published maps and institutional affiliations.

Ready to submit your research? Choose BMC and benefit from:

- fast, convenient online submission

- thorough peer review by experienced researchers in your field

- rapid publication on acceptance

- support for research data, including large and complex data types

- gold Open Access which fosters wider collaboration and increased citations

- maximum visibility for your research: over $100 \mathrm{M}$ website views per year

At BMC, research is always in progress.

Learn more biomedcentral.com/submissions 